\title{
ENTRE A CLAREZA E A RAZÃO: CONSIDERAÇÕES SOBRE DANTE AlighIERI na obra Della Perfetta Poesia ItALIANA, DE LUDOVICO MURATORI
} BETWEEN CLARITY AND REASON: CONSIDERATIONS ON Dante Alighieri in Della Perfetta Poesia Italiana BY LUDOVICO MURATORI

\section{Gustavo Luiz Nunes Borghi \\ ORCID 0000-0001-8817-9890}

Universidade de São Paulo São Paulo, SP, Brasil

\begin{abstract}
Resumo
Escrito em resposta às críticas francesas e inglesas dos séculos XVII e XVIII, Ludovico Muratori publica o Della Perfetta Poesia Italiana em 1706. Em seu tratado, o preceptista busca defender as letras italianas, fazendo uma revisão dos principais poetas de sua língua. A partir dos seus escritos, o presente artigo tem, por objetivo central, levantar a discussão sobre a recepção de Dante Alighieri na Itália, no início do século XVIII. Para tanto, num primeiro momento, apresentaremos algumas características e tópicas da poesia do final do século XVII e início do XVIII; em seguida, levantaremos as consideraçôes de Muratori sobre a noção de engenho, fundamental para as práticas letradas; por fim, discutiremos sua crítica à poesia de Dante Alighieri.
\end{abstract}

Palavras-chave: Poética, Dante Alighieri, Ludovico Muratori

\section{Abstract}

Written in response to the French and English critics of the $17^{\text {th }}$ and $18^{\text {th }}$ centuries, Ludovico Muratori published the Della Perfetta Poesia Italiana in 1706. In this work, the academic sought to defend Italian poetry, reviewing the main poets that wrote in his language. Based on Muratori's writings, this paper intends to discuss the reception of Dante Alighieri in Italy in the beginning of the $18^{\text {th }}$ century. We will first discuss some of the features and topics of the poetic art in the late $17^{\text {th }}$ and early $18^{\text {th }}$ centuries. We will then proceed to report some of the Muratori's comments about the notion of ingenium,

\section{Resumen}

Escrito en respuesta a las críticas francesas e inglesas de los siglos XVII y XVIII, Ludovico Muratori publica el Della Perfetta Poesia Italiana en 1706. En su tratado, el preceptista busca defender las letras italianas, haciendo una revisión de los principales poetas de su lengua. A partir de sus escritos, el presente artículo tiente, como objetivo central, discutir la recepción de Dante Alighieri en Italia, en el inicio del siglo XVIII. Para eso, en un primero momento, presentaremos algunas características y tópicos de la poesía de fines del siglo XVII y inicio del XVIII; después presentaremos las 
a key concept in poetic theory. Finally, we will discuss Muratori's critique of Dante Alighieri's poetry.

Keywords: Poetics, Dante Alighieri, Ludovico Muratori consideraciones de Muratori sobre la noción de ingenio, fundamental para las prácticas letradas; al fin, discutiremos su crítica a la poesía de Dante Alighieri.

Palabras clave: Poética, Dante Alighieri, Ludovico Muratori

A prática de escrever comentários sobre autores e suas obras é comum, desde os primeiros registros da poesia. Num esforço de compreendê-las, torná-las claras, ou ainda apresentar juízos, temos uma série de textos que versam sobre elas. Em letras latinas, destacam-se, por exemplo, os comentários de Sérvio à Eneida de Virgílio, compilados no século IV, os quais foram amplamente difundidos posteriormente. Em letras vernaculares, encontramos comentários e críticas às obras de Camóes, Tasso e Ariosto. Deste último, por exemplo, temos até uma pequena epístola que faz um discurso que a defende, como a de Giolito de Ferrara, na primeira edição de Orlando Furioso ${ }^{1}$.

Tais comentários nos revelam os mecanismos de apropriação das obras, como nos aponta Roger Chartier. Um texto, segundo o autor, não é um objeto estático cujas estruturas se mantêm as mesmas, independente da leitura que é feita; ao contrário, os textos são constantemente apropriados pelos leitores, produzindo novas interpretaçóes e representaçóes. O pesquisador sustenta:

a operação de construção de sentido efetuada na leitura (ou na escuta) como um processo historicamente determinado cujos modos e modelos variam de acordo com os tempos, os lugares, as comunidades. (CHARTIER, 1991, p. 178)

Os comentários das obras, aliados ao estudo de suas estruturas e suporte com que foram divulgadas, nos dão indícios de como a sociedade a recebeu e produziu novas significaçóes. Os comentadores e tratadistas têm papel fundamental nessa estrutura, pois nos auxiliam, nas palavras de Chartier, a compreender os usos e as interpretaçóes de um discurso. Ora, o mesmo ocorreu com a obra de Dante Alighieri, nos setecentos anos que separam a modernidade da publicação da maioria de seus textos. Certamente, durante os sete séculos de estudos, apropriaçóes e leituras, os escritos do poeta não foram sempre lidos da mesma forma, nem suas obras interpretadas a partir de uma única chave de leitura.

Neste breve artigo, discutiremos as consideraçóes traçadas sobre a obra de Dante por Ludovico Muratori, em seu tratado Della perfetta poesia italiana,

1 Trata-se da carta-prólogo, destinada ao Delfim da França e publicada em 1543. 
publicado no ano de 1706. Dividiremos o trabalho em quatro blocos: na primeira seção, discorreremos sobre a concepção de poesia que trataremos neste ensaio, e algumas características das letras do seiscentos; na segunda, introduziremos as noçóes gerais da poesia do setecentos, apresentando as principais mudanças, em relação ao período anterior, e chaves de leitura; em seguida, na terceira, apresentaremos uma carta de Voltaire em que há uma crítica à poesia de Dante; por fim, trataremos da obra de Muratori, expondo suas consideraçóes sobre o engenho, a poesia e o juízo e, por fim, seu comentário sobre o poeta florentino.

As práticas letradas: agudeza, engenho e arte

As práticas letradas e as artes, entre os séculos XVI e XVII, se organizavam segundo preceitos retórico-poéticos, sistematizados por uma série de textos desde o período antigo. De antemão, ao apresentarmos tal afirmação, excluímos as noçôes modernas de literatura, as quais apresentam critérios tais obra, público, subjetividade e mercado. Angelica Chiappeta (1997) aponta que a literatura surge com a sociedade burguesa e se consolida no século XIX. Tal disciplina também passou, segundo a autora, a excluir os textos que não fossem considerados 'literários', ou que apresentassem as categorias vigentes para o novo público leitor; desta forma, os comentadores das obras, como Muratori, e as preceptivas que versam sobre as artes retórico-poéticas foram deixadas de lado. Neste ensaio, discorreremos sobre outra noção de artes poéticas, ordenadas e organizadas segundo modelos de imitação e emulação, organizadas por preceptivas que versam sobre o fazer poético e retórico.

No século XV, no chamado 'Renascimento', muitas das obras do período antigo chegaram até nós: com a queda de Constantinopla, professores de retórica gregos se instalaram na Itália trazendo consigo preceptistas e pensadores antigos até então nunca lidos. Aldo Manuzio, como aponta Luisa Grigera (1994), passa a imprimi-los e, em pleno século XVI, temos sua ampla circulação. Deste movimento, os autores passaram a conhecer textos de Aristóteles, Longino, Teão, Hermógenes e Aftônio, influenciando as práticas letradas e de representação. Sua difusão se dá entre os círculos artísticos e educacionais, uma vez que são autores obrigatórios nos curriculuns dos colégios da Companhia de Jesus, que, desde sua criação, organiza e administra os centros de ensino nos reinos católicos - Portugal, Espanha e Estados Italianos - determinando quais autores e obras, bem como quais disciplinas seriam ensinadas. Em 1599, a ordem organizam a Ratio Studiorum, centrando-se nos escritos dos progymnásmata e nas Institutio Oratoria, de Quintiliano.

Formando os principais grupos dos reinos e Estados, a retórica e poética tomam papel central nessa sociedade, modelando as formas de comportamento 
e de representação social. Marc Fumaroli (1996) chama o período de Âge de l'éloquence, fazendo referência ao domínio e importância das práticas retóricas e poéticas na sociedade Europeia do século XVII. Roger Chartier (1991, p. 186), ao traçar a relação entre a sociedade de Antigo Regime e as práticas letradas, faz menção à representação, mecanismo pelo qual cada membro da sociedade se apresenta e manifesta:

Por considerar a posição "objetiva" de cada indivíduo como dependente do crédito que aqueles de que espera reconhecimento conferem à representaçấo que dá de si mesmo.

Como grande mecanismo retórico-poético deste século, podemos apontar a agudeza, constituída, segundo as preceptivas do período, como metáfora que produz um efeito de surpresa naquele que a decifra, evidenciando o engenho de quem a produziu. Por ser uma metáfora, aproxima elementos distantes e inesperados, sejam sonoros, visuais ou verbais. É chamada, nas letras italianas, de acutezza ou concetto e têm, como grandes preceptores, Emanuelle Tesauro, autor do Cannocchialle Aristotélico e o cardeal Sforza Pallavicino, autor do Delle Acutezze.

Clareza e razão: poética e retórica nos séculos XVII e XVIII

A tradição historiográfica, como nos aponta João Adolfo Hansen, classificou as produçóes letradas em 'escolas', ou 'movimentos' literários, os quais foram dispostos numa linha do tempo de forma que um sucedesse o outro. Ao tratar especificamente do Barroco, o pesquisador afirma que os blocos foram colocados de forma que, ao serem estudados, apresentem categorias que valham para todas as obras que o período compreende. Desta forma, o barroco, estudado pelo pesquisador, e o neoclassicismo, 'movimento' que o sucede, apresentam classificações que são aplicadas em todas as obras produzidas pelo período. Para nós, tal classificação exclui as particularidades das obras e dos autores, bem como deixa de lado certos gêneros e discussóes que não se enquadram na taxonomia proposta.

Pois bem, levantadas tais considerações, o chamado 'império da retórica' passa, na transição do século XVII para o XVIII, por sérios questionamentos e críticas que colocam sua hegemonia em questão. Sophie Conte (2008) levanta algumas das crises pelas quais a concepção de retórica e poética passaram, dando destaque ao desenvolvimento das ciências e seus métodos. Pierre de la Ramée é o primeiro a questionar a retórica, tal qual era proposta: das cinco partes - invenção, disposição, elocução, ação e memória - o francês acreditava que seria de competência da disciplina a elocução e ação, deixando, principalmente, a invenção e disposição para as ciências e para a lógica. 
Conte também aponta os escritos de Galileu, sucedidos por Descartes, como outro grande questionamento da disciplina: a crítica recairá sobre o silogismo - método dedutivo da lógica aristotélica e da retórica ${ }^{2}$ - e a defesa de um método próprio das ciências naturais, o qual será sistematizado já no século XVI (2008, p. 114):

Du point de vue de l'argumentation, Galilée, Bacon puis Descartes remettent en question la logique aristotélicienne dont le formalisme est peu fécond. Le syllogisme aristotélicienne a en effet davantage pour function d'exposer des résultats qu'il ne constitue une démarche scientifique de découverte ${ }^{3}$.

Tais consideraçóes, como aponta Conte, serão transpostas para as artes poéticas, as quais passaram a adotar os conceitos propostos pela nova filosofia no fazer poético. As discussōes sobre as tensōes entre a filosofia, a retórica e as artes neste período são complexas e exigem, conforme aponta a pesquisadora, mais fôlego; mas, do ponto de vista 'stylistique', os poetas, acadêmicos, críticos e preceptistas defenderão uma linguagem simples, clara e breve.

Desses críticos franceses, vale destacar Bernard de Lamy que será um dos primeiros estudiosos a propor uma nova arte poética e retórica, com sua obra La Rhetorique ou L'Art de Parler, publicada em 1675. Outro preceptista e crítico francês, Bernard de Fontenelle, em um tratado sobre a poesia, (1688) aponta a relação entre a poesia e as novas ciências:

Il n'est pas douteux que la philosophie n'ait acquis aujourd'hui quelques nouveaux degrés de perfection. De là se répand une lumière qui ne se renferme pas dans la région philosophique, mais qui gagne toujours comme de proche en proche, et s'étend enfin sur tout l'empire des lettres. L'ordre, la clarté, la justesse, qui n'étoient pas autrefois des qualités trop communes chez les meilleurs auteurs, le sont aujourd'hui beaucoup davantage, et même chez les médiocres. Le changement en bien jusqu'à un certain point est assez sensible partout. La poésie se piquera- $\mathrm{t}$ - elle du glorieux privilège d'en être exempte?

2 As relações entre a retórica e a lógica estão expostas em diversos trechos da obra de Aristóteles. Logo no início

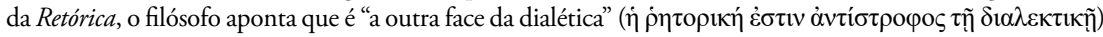

3 Do ponto de vista da argumentaçáo, Galileu, Bacon e em seguida Descartes, colocam em questão a lógica aristotélica, cujo formalismo não é muito fértil. O silogismo aristotélico está em desvantagem ao apresentar os resultados que não constitui um caminho de descoberta científica. - Tradução própria.

4 Não é duvidoso que a filosofia hoje em dia tenha adquirido novos degraus de perfeição. A partir de entâo propaga-se uma luz que năo se restringe à filosofia, mas que conquista outros aos poucos e de forma constante, e por fim se expande sobre o domínio das letras. A ordem, a claridade, a precisão, que antigamente não eram as qualidades dos melhores autores, hoje são mais comuns até nos medíocres. Essa boa mudança é percebida por todos. A poesia se orgulhará de seu glorioso privilégio de ser excluída dessa mudança? (Sur la Poesie, In: Ouvres de Fontenelle, p . 191-192) - Tradução própria. 
Segundo o francês, a filosofia estende suas propostas ao mundo das práticas letradas, impondo a elas novas categorias distintas das comuns ao período.

As propostas da nova poesia e retórica francesas seriam amplamente difundidas e adotadas no reino. Novamente Fumaroli (1996) aponta que os preceptistas e suas obras tiveram diversas impressóes feitas no decorrer do século XVII, sendo lidas em várias regiōes da Europa. Na Inglaterra, por exemplo, os poetas John Dryden e Alexander Pope tomam como modelos de críticos e de preceptistas os franceses Le Bossu, Boileau e Fontenelle.

Ao se impor o modelo de uma nova arte poética, amplamente influenciada pelas novas ciências e pela filosofia do século XVII e XVIII, os preceptistas e críticos passaram a criticar a poesia feita nos reinos católicos contrarreformados; de fato, teremos um constante ataque aos mecanismos poéticos e retóricos, em especial, a agudeza. Não serão poucos os autores que afirmarão que o procedimento afasta da verdade, ou ainda, que é fantasioso ou louco, como afirma Boileau nos versos de sua Art Poétique: dois versos da Arte Poética (vv. 43-44) de Boileau, em que o francês:

Evitons ces excès. Laisson à l'Italie

De touts ces faux brillants l'éclatante folie. 5

Em resposta, acadêmicos italianos passaráo por um movimento de revisão e mudança das práticas poéticas, seguindo os preceitos franceses e ingleses. No ano de 1690, surge a Arcádia Romana, instituição em que se reuniam os principais poetas e intelectuais da época para discutir poesia e retórica, como nos aponta Consoli e Petrocchi (1974). Os poetas adotaram os gêneros breves, como a écloga e algumas subespécies líricas - o soneto, o madrigal e a ode, por exemplo - e criticariam os modelos do século anterior, em especial Marino, Tasso e seus imitadores.

\section{Entre a razão e a clareza: a crítica de Dante nos setecentos}

Na carta Lettre sur le Dante, que compóe a obra Lettres sur les Anglais, publicada por Voltaire na metade do século XVIII, o filósofo francês dedica a Dante Alighieri algumas breves consideraçóes. Voltaire inicia a epístola afirmando que os italianos caracterizam o poeta florentino como divino, mas afirma que sua divindade é oculta, já que poucos conseguem lê-lo, "Les

5 Evitemos os excessos. / Deixemos para a Itália a brilhante loucura de todos os falsos brilhos. (Tradução própria) 
Italliens L'appellent Divin, mais c'est una Divinité cachée". Em seguida, de forma satírica, pontua que os italianos memorizaram apenas algumas poucas passagens, imaginando ser o suficiente para conhecer a obra como um todo. Nos parágrafos seguintes, o filósofo descreve a vida e lista algumas obras de Dante, dando destaque a Florença e aos conflitos políticos pelos quais a cidade passava em meados do século XIII.

Em seguida, o filósofo francês passa a descrever os primeiros cantos do Inferno, destacando o encontro entre Dante e Virgílio, sua entrada no mundo dos mortos através dos Portóes de São Pedro, a travessia feita por Caronte, e o contato com os poetas e filósofos da antiguidade:

[...] découvrent dans l'Enfer ses demeures três agréables: dans l'une font Homére, Horace, Ovide, \& Lucain; dans une autre voit Electre, Hector, Enée, Lucrèce, Brutus, \& le Turc Saladin; dans une troisiéme Socrate, Platon, Hippocrate, \& l'Arabe Averroes. ${ }^{7}$

Em seguida, o francês passa a questionar os elementos constitutivos do gênero da Commédia:

Enfin parait le véritable Enfer, \& où Pluton juge les condamnés. Le voyageur y reconnait quelques Cardinaux, quelquer Papes, $\&$ beaucoup des Florentins. Tout cela est-il dans le style comique? Non. Tout cela est-il dans le genre héroique? Non. Dan quel goût est donc ce Poeme? Dans um goût bizarre ${ }^{8}$.

Após sucessivas perguntas e indagaçóes sobre o gênero do poema, Voltaire chega à conclusão de que a obra é de um gosto bizarro. Para o francês, a Commedia do poeta florentino não estaria de acordo com os preceitos dos gêneros cômico ou heroico, aos quais poderia se filiar, causando o estranhamento que o francês reconhece como bizarre, que, de acordo com o Dictionaire de la Langue Française, pode significar o que náo é de juízo, ou o que não é racional.

6 Os italianos o chamam de Divino, mas é uma Divindade oculta. (Lettre sur le Dante, In: Poetique de M. de Voltaire, p. 547) - Tradução própria .

7 [...] eles descobriram alguns agradáveis residentes no inferno: de um lado estão Homero, Horácio, Ovídio \& Lucano; de outro, vêm Electra, Heitor, Enéias, Lucrécio, Burto e o turco Saladino; o trio Sócrates, Platão e Hipócrates, e o árabe Averróis. (Lettre sur le Dante, In: Poetique de M. de Voltaire, p. 550) - Tradução própria.

8 Por fim o inferno surge, onde Plutão julga os condenados. O viajante reconhece alguns cardeais, alguns papas e muitos florentinos. Tudo isso pertence ao gênero cômico? Não. Pertence ao gênero heroico? Não. Então, qual é o gosto deste poema? É um gosto bizarro. (Lettre sur le Dante, In: Poetique de M. de Voltaire, p. 550) - Tradução própria .

9 Voltaire retoma a taxonomia dos gêneros e a o termo 'gosto bizarro' de Racine em seu tratato Reflexions générales sur la poesia épique, publicado em 1757. 
Os escritos de Voltaire sobre Dante reverberaram nos círculos poético e acadêmico italianos. Vicenzo Martinelli, um italiano que vivia em Londres à época, passa a responder Voltaire e denunciá-lo. Em seguida, diversos poetas escreveráo respostas ao francês, muitos o defendendo e outros o criticando, numa polêmica e embate que durarão mais de vinte anos. Voltaire não foi o único que, em meados do seiscentos e setecentos, criticou a obra de Dante; também a criticaram autores como Fontenelle, René Rapin e Boileau. $\mathrm{O}$ filósofo francês foi um dos principais representantes da poesia do século XVIII, influenciada pelas ideias da ilustração e dos embates anteriores, já mencionados.

Sobre a Oscurità di Dante: divisão de engenhos e o papel das artes no Della Perfetta Poesia Italiana

Ludovico Muratori, na obra Della perfetta poesia italiana, faz um balanço das letras italianas até o século XVIII. Como apontam Consoli e Petrocchi (1978), o século XVIII inaugurará uma nova modalidade de gênero: o das histórias da poesia. Seguindo o ímpeto dos enciclopedistas em classificar o saber, os poetas e acadêmicos passarão a fazer grandes narrativas das letras dos seus reinos; elas, entretanto, não seguirão um modelo teleológico ou progressista, mas serviráo como um catálogo em que estariam listados os principais poetas e oradores, bem como suas principais obras. Ludovico Muratori não inaugurou a tentativa de aplicar os conceitos da poesia francesa nas letras italianas, nem responder as críticas feitas pelos intelectuais aos poetas de sua língua. Glovan-Gioseffo Orsi foi o primeiro a fazê-lo, em sua obra Considerazioni, publicada no ano de 1703. Segundo James Sambrook (2005) ela não foi bem recebida, sendo satirizada por Voltaire, anos depois, quando o francês afirmou "deux très-gros volumes pour justifiquer quelques bers $d u$ Tasse $e^{10}$ ".

No capítulo oitavo do Della Perfetta Poesia Italiana, o letrado faz uma crítica à obra espanhola do século passado, baseando-se em conceitos das letras francesas e inglesas. Como nos aponta Ivan Teixeira (2002, p. 134), "o primeiro ataque sistemático contra o estilo agudo, de que ele [Góngora] é o maior representante, surgiu com o livro Della Perfetta Poesia Italiana". Segundo Mercedes Blanco (1992, p. 431), "Les mellieurs esprits, Muratori en Italie, Luzán et Mayans en Espagne, sont, au début du XVIIIe siècle, dans le champ des adversaires du concepto" 11 , e continua

10 Dois grossos volumes para justificar um par de versos de Tasso (Oeuvres Complètes de Voltaire, p. 226) - Tradução própria.

11 As melhores mentes, Muratori na Itália, Luzan e Mayan na Espanha, estão, no início do século XVIII, no campo dos adversários do conceito. - Traduçáo Própria. 
Leur attitude envers le conceptisme, non seulement tel que le représentent ses théoriciens, mais aussi tel que le pratiquaient les poètes, les dramaturges, les prédicateurs de ce que nous appelons le Baroque, est très sévèrement critique ${ }^{12}$.

Como nos aponta a pesquisadora, Muratori foi o primeiro a, de forma ampla, adotar os preceitos e características da nova poesia francesa, deixando claras sua filiaçáo aos preceitos estabelecidos pela Arcádia Romana, em 1690, intimamente atrelados às propostas da nova poesia francesa e inglesa. Também passa a criticar os poetas do século anterior, adeptos da poesia aguda. Ao elencar os poetas espanhóis, Muratori aponta que sua poesia é inverossímil (1971, p. 475):

Potrebbe pascersi la curiosità nelle Opere del Gongora,del Villamediana, di Lope, e di D. Francesco de Quevedo. Né ciò si crede da qualcun di loro biasimevole, perché essendo gl'Ingegni Spagnuoli naturalmente nello stesso ragionamento famigliare acutissimi, penetranti, e sottili, [...] Cercano essi perciò ragioni sottilissime, che noi chiameremmo bene spesso troppo acute, inverisimili, ed oscure.

Já no nono capítulo, antes de passar a discutir Dante, Muratori começa a tratar dos tipos de engenho, dividindo-os em músico, amatório e filosófico. Vale lembrar que a noção de engenho, fundamental para as preceptivas antigas, seria uma característica natural do homem, produzindo as metáforas, os conceitos e as imagens poéticas. Ao lado do exercício e da técnica, o engenho compóe uma das principais características do poeta e do orador. Tal noção se distancia das noçôes românticas de autor, obra, público, subjetividade, originárias do século XIX, e se aproxima das noçôes da retórica e poética antigas, aos regimes de imitação e emulação que ordenam as práticas de representação anteriores ao movimento romântico. No século XVI, o engenho se classifica como qualidade natural do homem, sendo uma faculdade capaz de buscar os melhores tópicos para a inuentio, muitas vezes identificado com a imitatio. No século XVII, segundo João Adolfo Hansen (2002), o engenho seria classificado em três tipos: o "natural", o "furioso" e o "exercitado". No início do capítulo, Muratori aponta a importância do engenho para a poesia (1971, p. 482):

Dico adunque, che a formare un Poeta eccellente non solamente si richiede una pronta, chiara, e feconda Fantasia, un'acuto, e vivace Ingegno; ma che è ancor necessario quell'Ingegno universale.

12 Sua atitude de voltar-se ao conceptismo, não somente os teóricos que o representam, mas também os poetas que o praticam, os dramaturgos, os predicadores, do chamado barroco, os quais são severamente criticados. - Tradução Própria. 
Muratori apresenta uma nova definição, tripartindo o engenho em três grupos: o musical, o amatório e o filosófico. O engenho musical, segundo Muratori, se define como aquele que busca o belo pela harmonia das palavras, dos sons e da forma das composiçóes poéticas; o amatório, que busca a beleza de maneira superficial, não penetra na beleza interna, centrando-se no ornamento das palavras e nas imagens por ela criadas; e o filosófico, que se define como aquele capaz de penetrar na essência das coisas, pode distinguir o falso do verdadeiro. Muratori divide os engenhos de acordo com sua funçáo na composição do discurso poético: um se preocupa com os recursos sonoros, aspecto primeiro da poesia, como as rimas, a cadência e a métrica; o segundo, com a beleza externa, como a disposição das figuras e dos tropos do discurso; e, por fim, o terceiro vale da beleza interna daquilo que se quer dizer, distinguindo (1971, p. 483):

il Vero dal Falso, il sodo dal ridicolo, il Bello verace dal finto, argomentando su qualsivoglia cosa, e concependo sentimenti nobili, pellegrini, dilicati, secondoché ne dà campo la Materia proposta.

Para o autor, os três trabalham em harmonia, uma vez que são imprescindíveis para o poeta. Sem o engenho musical, o verso carecerá de harmonia e número, sendo de difícil apreciação; sem o amatório, carecerá do ornamento do discurso; e sem o filosófico, não conseguiria tratar da essência daquilo que se quer dizer.

Após organizar e classificar os engenhos, Muratori passa a buscá-los nos poetas italianos: começa por mencionar os chamados medievais, ou " $i$ primi Rimatori d'Italia", os quais, segundo ele, são detentores de um grande engenho musical, reconhecidos quando se apenas os ouve; em seguida, menciona os poeta do Parnaso de "vecchi Poeti Italiani", os quais mostrariam um grande engenho amatório, citando como exemplo Petrarca, Boiardo e Ariosto. Ao citar o engenho filosófico, Muratori evidencia sua filiação aos preceptistas franceses e ingleses de seu século, uma vez que, para ele, o tal engenho penetraria na essência da matéria, evidenciando a verdade daquilo que se quer dizer, por meio da razão (1971, p. 486):

Penetravano essi co' lor pensieri nell'interno della Materia, e scoprivano da per tutto bellissime Verità, e sontuose ragioni, che poi servivano a rendere internamente bello, e pellegrino il lor lavorio.

Muratori, em seguida, passa a defender a poesia italiana, afirmando que ela já conseguiu atingir tal grau de engenho filosófico, e que os poetas presentes - do século XVIII, influenciados pela Arcádia Romana - já o detêm e o praticam em suas poesias, e que os anteriores, por mais que não tivessem 
o filosófico, foram mestres nos outros dois engenhos. Petrarca, a seu ver, seria o grande poeta até então, o qual melhor conseguiu organizar e dispor dos três; Marino, por outro lado, possuía muito engenho amatório, compondo obras muito longas e de difícil apreensão da verdade.

Em seguida, Muratori conclui a disposição sobre os engenhos expondo a organização do saber humano: para ele, a ciência seria dividida em três grandes áreas: a filosofia das coisas, ou física, que tem como objeto os elementos da natureza; a dialética, ou lógica, que busca a verdade; e a filosofia do coração, que seria a moral e buscaria o bem. Para ele, as duas últimas seriam essenciais aos poetas (1971, p. 498):

Ma ripigliando il preso ragionamento, e passando dalla necessità, che hanno i Poeti d'apprender la Filosofia de' Costumi, a quella della Logica, dico che questa Arte, a cui va congiunta la Metafisica, o sia essa collo studio appresa, o infusa nell'Intelletto nostro dalla bene- fica Natura, è altresí necessaria per iscoprire i bei lumi, le nobili Verità, e ragioni, che son come i metalli sepolte nelle miniere delle cose.

Após a exposição, retoma os poetas antigos e sua relação com o engenho musical, Muratori passa a discorrer sobre Dante. Ao comentar o poeta florentino, não omite os epítetos pelos quais fora caracterizado (1971, p. 501):

gran Filosofo Dante, non v'ha dubbio, che le Opere loro ci sarebbon piú care, e questi con piú ragione avrebbe ottenuto il soprannome di Divino.

Aponta, poucas linhas depois, que Dante era dotado dos engenhos musical e filosófico, compondo suas obras com maestria, e afirma que o principal problema de sua obra seria a escuridão, ou a oscurità. Segundo o letrado, Dante usa apenas o engenho amatório, assim como boa parte de seus contemporâneos; tal engenho, como já pontuado por Muratori, auxilia nas imagens e adereços dos versos, mas, quando usado em excesso, pode distanciar da verdade e beleza aquele que lê. Logo, a oscurità de Dante se encontra não em sua matéria, mas na forma com que escreve. Para Muratori, o poeta se aproxima dos escolastas que, em suas palavras, têm uma linguagem bárbara. Segundo o tratadista, a poesia deve ser clara e o poeta deve falar com o povo e não apenas com os peripatéticos.

Encontramos, nos breves parágrafos sobre Dante, sua crítica feita por Muratori, bem como a exposiçáo de sua poética: o letrado se propóe, desde o início de sua obra, a fazer uma defesa da poesia italiana que, como mencionamos, estava sob ataque dos críticos franceses. Logo, ela não é uma mera apologia, ou exaltação das qualidades dos poetas italianos; pelo contrário, 
Muratori expóe sua concepção de poesia e de arte poética - atrelada, como já dissemos, aos pressupostos franceses - aplicando-a nos poetas elencados. Dante, diferentemente da epístola de Voltaire, ainda é, no Della Perfetta Poesia Italiana, o grande poeta italiano, autor de obras fundamentais; é escuro na medida em que não é claro, ou seja, na medida em que não se atrela às novas concepçóes de poesia do século XVIII. Desta forma, Muratori evidencia que as noçóes de clareza e razáo, típicas de seu tempo, são de seu tempo, desconhecidas pelos poetas do passado. Mas, mesmo que os poetas do passado náo apresentem as características da nova poesia, não quer dizer que não apresentem qualidades e não sejam importantes para a arte.

\section{Considerações finais}

As obras de um poeta não são lidas e recebidas de forma única, no transcorrer do tempo. Entre a publicaçâo dos escritos de Dante Alighieri e os estudos contemporâneos, diversos séculos se passaram, acumulando olhares, chaves de leitura e modos de interpretar seus escritos. A interpretação da obra é moldada segundo o contexto em que o crítico se insere, como ocorreu com Ludovico Muratori, em seu tratado, publicado no início do século XVIII.

Evitando as periodizaçóes e classificaçóes da literatura, apresentamos a mudança sofrida pelas práticas letradas: de uma poesia aguda, difundida pela Companhia de Jesus e reproduzida nos círculos cortesóes das monarquias ibéricas e Estados italianos para uma arte clara, breve e organizada sob os preceitos da razão. Da França para a Inglaterra e Itália, e em seguida para as demais monarquias europeias, tal modelo se torna hegemônico na Europa no início do século XVIII.

$\mathrm{Na}$ Itália, seguindo as letras e preceptivas francesas e as discussóes da Arcádia Romana, Ludovico Muratori escreve o Della Perfetta Poesia Italiana, já no início do século. Ao fazer uma revisão da poesia italiana, o preceptista expóe sua noçáo de arte e engenho, alinhadas aos preceitos da ilustração. Ao tratar de Dante Alighieri se diferencia de Voltaire, uma vez que o caracteriza como grande poeta de sua língua, atestando sua divindade; mas, afirma que sua oscurità vem de um não conhecimento de uma nova poética, comum de seu tempo.

\section{Referências}

ARISTÓTELES. Poética. Trad. Eudoro de Souza. São Paulo: Abril Cultural, 1979. ARISTÓTELES. Retórica. Madrid: Alianza Editorial: 2002.

BLANCO, Mercedes. Les Rhétoriques de la Pointe. Baltasar Gracián et le conceptisme en Europe. Paris: Librairie Honoré Champion, 1992. 
BOILEAU DESPREAUX, Nicolas. Arte poética (1674). Tradução Celia Berrettini. Sáo Paulo: Perspectiva, 1979.

BOILEAU, Nicolas. L'art poétique, 1. Euvres complètes. Paris: Les Belles lettres. 1952.

BOUHOURS, Dominique. La Manière de Bien Penser dans les ouvrages d'esprit. Dialogues. Paris: A Paris ches la veuve de Sebastien Mabre-Cramoisy, Imprimeur du Roy, Rue Saint Jacques, aux Cicognes, 1688.

CARR, Thomas. Descartes and the resilience of rhetoric. Illinois: Southern Illinois University Press, 2009.

CARVALHO, Maria do Socorro Fernandes de. Poesia de agudeza em Portugal. São Paulo: Humanitas; EDUSP; FAPESP, 2007.

CHARTIER, Roger. O mundo como representação. Estudos avançados, v. 5, n. 11, p. 173-191, 1991.

CHIAPPETTA, Angelica. Ad animos faciendos: comoção, fé e ficção nas Partitiones Oratoriae, e no De Officiis, de Cicero. Tese (Doutorado). FFLCH-USP. São Paulo, 1997.

CONSOLI, Domenico, PETROCCHI, Giorgio. La Letteratura Italiana. Arcadia, Illuminismo, Romanticismo. Miláo: Sansoni / Accademia, 1974.

CONTE, Sophie. La rhétorique au XVIIe siècle: un règne contesté. Modèles linguistiques, v. 29, n. 58, p. 111-130, 2008.

CRONK, Nicholas. The Classical Sublime: French Neoclassicism and the Language of Literature. Charlottesville, VA: Rockwood Press, 2003.

DEMÉTRIO, LONGINO. Sobre el estilo. Sobre lo sublime. Introducción, traducción y notas de J. García López. Revisada por C. García Gual. Madrid: Editorial Gredos, 2008.

DESCARTES, René. Discurso do Método. São Paulo: Martins Fontes, 2014.

DESCARTES, René. Regras para a condução do espirito. Lisboa: Ediçôes 70, 1970.

FONTENELLE. Oeuvres de Fontenelle, des Académies françoise, des sciences, des Belles-Lettres, de Londres, de Nancy, de Berlin et de Rome. Tome Troisième. Paris: Bastien e Servieres Libraires, 1790.

FUMAROLI, Marc. L'âge de l'éloquence. Paris: Albin Michel, 1996.

GRIGERA, Luisa López. Retórica en España del Siglo de Oro. Salamanca: Universidad de Salamanca, 1994.

HANSEN, João Adolfo. Fênix Renascida \& Postilhão de Apolo: uma introdução. In: PÉCORA, Alcir: Poesia Seiscentista. São Paulo: Hedra, 2002.

HANSEN, João Adolfo. Retórica da agudeza. Letras Clássicas, n. 4, São Paulo, 2000. 
LAMY, Bernard. La Rhétorique ou l'art par le R. P. Bernard Lamy, Prêtre de l'Oratoire. Nouvelle édition, revue \&argumentée, où l'on a ajouté ses Nouvelles reflexions sur l'art poétique. Paris: A Paris, Chez Lyon, 1757

MURATORI, Ludovico. Della perfetta poesia italiana. Milano: Einaudi, 1971.

NISBET, H; RAWSON, C. The Cambridge History of Literary Criticism. v. 4, The Eighteenth Century. Reino Unido: Cambridge University Press, 2005.

NORMAN, Larry. The shock of the ancient. Literature \& History in Early Modern France. Chicago: Chicago University Press, 2011.

SAMBROOCK, James. Poetry, 1660-1740. In: NISBET, Barry, RAWSON, CLaude. The Cambridge History of Literary Criticism. Cambridge: Cambridge University Press, 2005, v. 4, p. 75-116.

TEIXEIRA, Ivan. Mecenato Pombalino e poesia neoclássica. São Paulo: EDUSP; FAPESP, 2002.

VOLTAIRE. Oeuvres de Voltaire. Siècle de Louis XIV; Siècle de Louis XV; Annales de L'Empire; Histoire du Parlement de Paris; Mélanges Historiques. Tome Quatrième. Paris: Bacquenois Editeur, 1838.

VOLTAIRE. Poetique de M. de Voltaire, ou Observations Recuellies de ses Ouvrages. Premiere Partie. Genebra: Lacombe Librarie, 1766.

Gustavo Luiz Nunes Borghi. Bacharel em letras (português/latim) pela Universidade de São Paulo. Licenciado em letras - português pela USP. Mestre em Literatura Portuguesa pela Universidade de Sáo Paulo. Pós-Graduando em Filosofia Antiga na PUC-Rio. Doutorando em Literatura Espanhola na Universidade de São Paulo. Atua nas áreas de retórica, poética. É membro da Sociedade Brasileira de Estudos Clássicos; da Associação Brasileira de Hispanistas; e sócio-fundador da Sociedade Iberoamericana de Retórica. Foi bolsista da Real Academia Galega em curso na Universidade de Santigado de Compostela. Realizou um trabalho de revisão cultural para a Xunta de Galícia, órgão subsidiado pelo Real Ministério de Cultura da Espanha. Foi bolsista, por três vezes seguidas, de graduação na FFLCH/USP, nas disciplinas de Introdução ao Latim, Língua Latina I e Filologia Portuguesa. É membro dos grupos de pesquisa "Cervantes: poética, retórica e formas discursivas na Espanha dos séculos XVI e XVII", "Historiografia das Letras Luso-Brasileiras e da Literatura Brasileira” e "A tradição literária italiana”, na Universidade de Sáo Paulo e Universidade Federal de São Paulo. Entre 2011 e 2019 foi professor de língua portuguesa, literatura lusófona e produção textual no Colégio FECAP, tendo atuado nos três anos regulares do Ensino Médio. É monitor-bolsista PAE de graduação na Disciplina "FLM0621 - Literatura Espanhola: Século XVII”. Atualmente é professor de Língua e Literatura Portuguesa no Middle Years Programme (MYP-IB) da Escola Internacional de Alphaville.

E-mail: gustavo.borghi@usp.br 